\title{
Conservative management of vesicovaginal fistula: a rare case report
}

\author{
Deepa Shanmugham $^{1 *}$, Siritha Kondra ${ }^{1}$, S. Vasudevan ${ }^{2}$
}

\begin{abstract}
${ }^{1}$ Department of Obstetrics \& Gynaecology, Aarupadai Veedu Medical College, Pondicherry, India
${ }^{2}$ Department of Urology, Aarupadai Veedu Medical College, Pondicherry, India
\end{abstract}

Received: 23 February 2016

Accepted: 18 March 2016

\section{*Correspondence:}

Dr. Deepa Shanmugham,

E-mail: drdeepabalamurugan @gmail.com

Copyright: (c) the author(s), publisher and licensee Medip Academy. This is an open-access article distributed under the terms of the Creative Commons Attribution Non-Commercial License, which permits unrestricted non-commercial use, distribution, and reproduction in any medium, provided the original work is properly cited.

\begin{abstract}
Vesicovaginal Fistula is a debilitating condition that has affected women for millinea. Spontaneous closures of VVF with continuous bladder drainage for varying periods have been reported by few authors. Here we present a case of post hysterectomy VVF managed conservatively. A 45 year old parous woman presented with continuous leakage of urine following hysterectomy. The clinical diagnosis of Vesicovaginal Fistula was proven by cystoscopy and CT cystography. VVF healed by continuous bladder drainage for 4 weeks. Non-surgical treatment with continuous bladder drainage can also result in complete healing of small VVFs.
\end{abstract}

Keywords: Vesicovaginal fistula, Catheter, Hysterectomy

\section{INTRODUCTION}

Vesicovaginal fistula (VVF) has been one of the most unfortunate accompaniments of the virtue of procreation bestowed upon womanhood. The earlier evidence of VVF was found in 1923, when Derry examined the mummified body of Henher, a lady in the court of Mentuhotop of the $11^{\text {th }}$ dynasty who reigned around 2050 BC. ${ }^{1}$ But still, VVF continues to remain a challenge for gynecologic surgeon. The incidence of post-surgical VVF ranges from 1 in 750 to 1 in 1200 based on various studies, with abdominal hysterectomy for benign condition on uterus being the most common cause. ${ }^{2,3}$ Patients with post hysterectomy VVF are distraught, as a routine procedure has resulted in a complication that may be worse than the original symptoms and so these patients will be reluctant to undergo further surgical repair. Successful conservative management via continuous bladder drainage with catheter for small VVF has been described in medical literature. Here, we present a case of post hysterectomy VVF managed conservatively.

\section{CASE REPORT}

A 43 year old parous woman presented to our gynecological outpatient department with the complaints of urinary incontinence for the past 4 days with symptoms being aggravated by coughing and sneezing. She had undergone abdominal hysterectomy 1 month back for adenomyosis elsewhere. Her intra operative and postoperative period was uneventful and she was apparently well on discharge. She gave negative history for urge incontinence. Her past history revealed no medical problems.

On general physical examination, she was not anemic and her vital signs were stable. Abdomen was soft, nontender, with no palpable mass. Operated pfannensteil scar was healthy. Per speculum examination revealed leakage of urine from the vaginal vault, but the exact site could not be located. On Moir's three swab test, the highest swab was soaked with methylene blue dye suggestive of urinary fistula.

On cystoscopy, there was an irregular raw area at the base of the bladder, probably fistulous opening, around $2 \mathrm{~cm}$ away from both ureteric orifices. Contrast CT 
cystography revealed a small vesicovaginal fistula of size $3 \mathrm{~mm}$ (Figure 1). Ureters were not involved. Based on the above investigations, a diagnosis of post hysterectomy vesicovaginal fistula was made.

Considering the smaller size of the fistula and earlier diagnosis, the decision for conservative management with continuous bladder drainage was taken. After getting informed consent, she was on bladder catheterization for 4 weeks. After 4 weeks, catheter was removed and she remained dry. Per speculum examination also revealed no leakage of urine. Patient was discharged after one week in apparently normal condition. When the patient was reviewed after 4 weeks, she was totally asymptomatic.

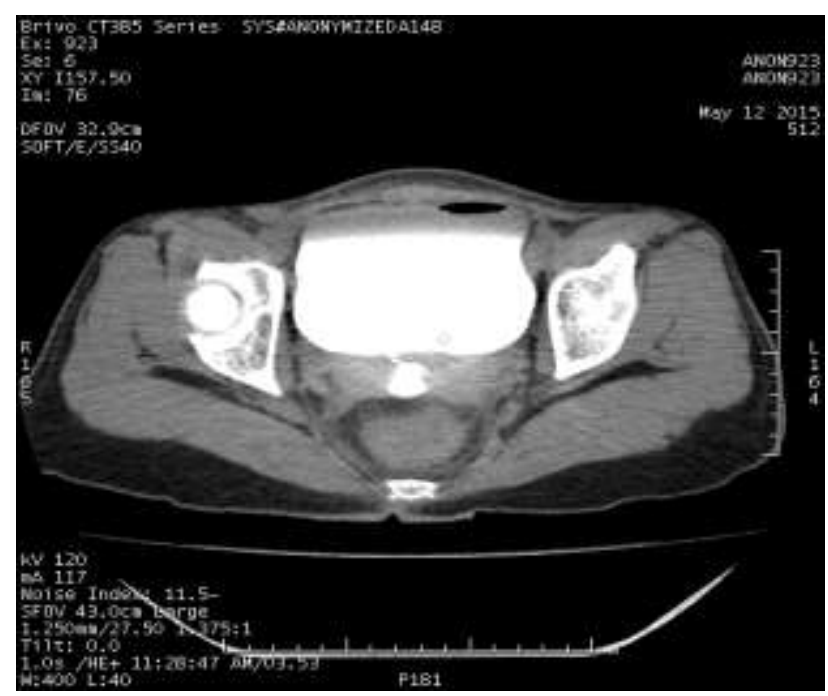

Figure 1: Contrast CT cystography showing vesicovaginal fistula.

\section{DISCUSSION}

Vesicovaginal Fistula is one among the most distressing complications of gynecologic and obstetric procedures. Women with VVF continue to suffer year after year as they become socially outcast due to continuous smell of urine. Though obstetric fistulas have been on decline in modern obstetrics, there is an increasing trend in the etiology of VVF attributed to gynecological cause ${ }^{5}$. VVF following hysterectomy is most likely to arise from an unrecognized bladder injury at the time of surgery, which results in the formation of an urinoma. Other causes include pressure necrosis due to inappropriate placement of haemostatic suture and/or devascularisation injury to the tissue.

Classically, the post-operative VVF presents with continuous leakage of urine from the vagina. The time of presentation peaks at 7-10 days after surgery, but may be variable, ranging from 4-6 weeks after surgery. ${ }^{6}$ In the case of less obvious fistula, a dye test is performed to visualize the passage of fluid through the fistula.
Cystoscopy is a crucial adjunct and it should be done in all patients. It can reveal the size and number of fistula, relation to ureteral orifices and foreign bodies (sutures). Patients with VVF need a mandatory intravenous pyelogram (IVP) for upper urinary tract evaluation as there may be an associated ureterovaginal fistula in $10 \%$ of patients ${ }^{6}$. Three dimensional contrast CT cystography provides excellent delineation of the fistula as in our case, but more studies are needed to prove its superiority over IVP in the diagnosis of VVF.

The key for the prevention of fistula at the time of gynecologic surgery is mobilization and correct dissection of bladder. Other measures include adequate exposure; minimize bleeding and hematoma formation and recognition of intra operative bladder injury.

Regarding the management, several techniques have been described for surgical repair of VVF through different routes. Conservative management of small VVF by continuous bladder drainage has been proven successfully by few authors. ${ }^{4,-9}$ Davits and Miranda described successful treatment of post hysterectomy VVF, where the treatment involves simple bladder drainage for periods ranging from 19-54 days. ${ }^{4}$

Ridder D et al described the pathophysiology behind the spontaneous closure of VVF in patients with continuous bladder drainage. He stated that before epithelialization is complete, and the abnormal communication between viscera will tend to close spontaneously, provided that urine is diverted from the fistula. In his study, the overall spontaneous closure rate was $13 \%$ in small fistula of $3 \mathrm{~mm}$ diameter. ${ }^{7}$

Zimmern concluded that if the fistula is small and the patient's vaginal leakage of urine is cured with Foley's catheter placement, the fistula has a high spontaneous cure rate with Foley's drainage for 3 weeks. ${ }^{8}$

Elkins and Thompson noted that success with continuous bladder drainage was unpredictable for the individual patient with overall success rates ranging from $12-80 \%$. Successful cases were characterized by the following criteria: Continuous bladder drainage for up to 4 weeks, the VVF was diagnosed and treated within 7 days of index surgery, size of VVF was less than $1 \mathrm{~cm}$, and they were not associated with carcinoma or radiation. ${ }^{9}$

\section{CONCLUSION}

Urinary fistulas cause immense physical and psychosocial problems in women's life. Their successful management poses a significant challenge for the treating gynaecologists. Although surgical repair remains the mainstay of treatment, conservative management has a definitive role in managing small vesicovaginal fistula. 
Funding: No funding sources

Conflict of interest: None declared

Ethical approval: Not required

\section{REFERENCES}

1. Derry DE. Note on five pelves of women in the eleventh dynasty in Egypt. J obstet gynaecol $\mathrm{Br}$ Emp. 1935;42:490.

2. Hilton P, Cromwell DA. The risk of vesicovaginal \& urethrovaginal fistula after hysterectomy performed in the English National Health Service - a retrospective cohort study examining patterns of care between $2000 \& 2008$. Br J obstet gynaecol. 2012;119:1447-54.

3. Harkki-Siren P, Sjoberg J, Tiihnen A. Urinary tract injuries after hysterectomy. Obstet gynaecol. 1998;92:113-8.
4. Davits RJ, Miranda SI. Conservative treatment of vesicovaginal fistulas by bladder drainage alone. $\mathrm{Br} \mathbf{J}$ Urol. 1991;68(2):155-6.

5. Tancer ML. Observations on prevention and management of vesicovaginal fistula after total hysterectomy. Surg gynaecol obstet. 1992;175:501-6.

6. Sam D, Graham, Thomas E. Keane. Vesicovaginal fistula .Glenn's urologic surgery. Chapter 20:130-31.

7. De Ridder D. Surgical treatment of obstetric fistula. In: Obstetric fistula in the the developing world, $4^{\text {th }}$ international consultation on incontinence, committee 18, Paris July 5-8, 2008.

8. Zimmern PE, Hadley HR, Staskin D. Genitourinary fistulas vaginal approach for repair of vesicovaginal fistulas. Urol Clin North Am. 1985 May;12(2):361-7.

9. Elkins T, Thompson J. Lower urinary tract fistulas. Walters M, Karram M, eds. Urogynecology and Reconstructive Pelvic Surgery. St. Louis, MO: mosby. 1999:355-66.

Cite this article as: Shanmugham D, Kondra S, Vasudevan S. Conservative management of vesicovaginal fistula: a rare case report. Int J Reprod Contracept Obstet Gynecol 2016;5:1643-5. 